\title{
Tissue-specific insulin resistance in mice with mutations in the insulin receptor, IRS-1, and IRS-2
}

\author{
Yoshiaki Kido, ${ }^{1}$ Deborah J. Burks, ${ }^{2}$ Dominic Withers, ${ }^{2}$ Jens C. Bruning, ${ }^{2}$ C. Ronald Kahn, ${ }^{2}$ \\ Morris F. White, ${ }^{2,3}$ and Domenico Accili ${ }^{1}$ \\ ${ }^{1}$ Developmental Endocrinology Branch, National Institute of Child Health and Human Development, \\ National Institutes of Health, Bethesda, Maryland 20842, USA \\ ${ }^{2}$ Research Division, Joslin Diabetes Center, Harvard Medical School, Boston, Massachusetts 02215, USA \\ ${ }^{3}$ Howard Hughes Medical Institute, Boston, Massachusetts 02215, USA
}

Address correspondence to: Domenico Accili, Berrie Research Pavilion, 1150 St. Nicholas Avenue, Room 238A, New York, New York 10032, USA. Phone: (212) 304-7391; Fax: (212) 304-7390; E-mail: da230@columbia.edu.

Yoshiaki Kido's and Domenico Accili's present address is: Naomi Berrie Diabetes Center, Department of Medicine, College of Physicians and Surgeons of Columbia University, New York, New York 10032, USA.

Received for publication July 20, 1999, and accepted in revised form November 23, 1999.

Type 2 diabetes is characterized by abnormalities of insulin action in muscle, adipose tissue, and liver and by altered $\beta$-cell function. To analyze the role of the insulin signaling pathway in these processes, we have generated mice with combined heterozygous null mutations in insulin receptor (ir), insulin receptor substrate (irs-1), and/or irs-2. Diabetes developed in $40 \%$ of $\mathrm{ir} / \mathrm{irs}-1 / \mathrm{irs}-2^{+/-}, 20 \%$ of $\mathrm{ir} / \mathrm{irs}-1^{+/-}, 17 \%$

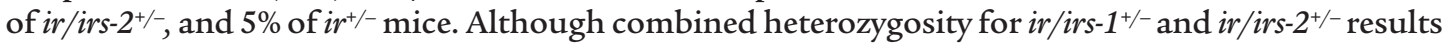
in a similar number of diabetic mice, there are significant differences in the underlying metabolic abnormalities. $\mathrm{ir} / \mathrm{irs}-1^{+/-}$mice develop severe insulin resistance in skeletal muscle and liver, with com-

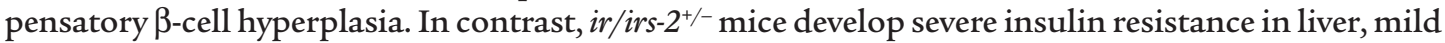
insulin resistance in skeletal muscle, and modest $\beta$-cell hyperplasia. Triple heterozygotes develop severe insulin resistance in skeletal muscle and liver and marked $\beta$-cell hyperplasia. These data indicate tissue-specific differences in the roles of IRSs to mediate insulin action, with irs-1 playing a prominent role in skeletal muscle and irs-2 in liver. They also provide a practical demonstration of the polygenic and genetically heterogeneous interactions underlying the inheritance of type 2 diabetes.

J. Clin. Invest. 105:199-205 (2000).

\section{Introduction}

The pathogenesis of type 2 diabetes is controversial (1, 2). Although most data indicate that insulin resistance is an early abnormality in the clinical history of the disease, it is generally accepted that insulin resistance per se is not sufficient to cause overt diabetes. Abnormalities of $\beta$-cell function are also present, although more elusive to demonstration, in the preclinical stage of type 2 diabetes (3). The interdependence of multiple tissues in determining overall metabolic control begs the question of whether the primary abnormality in type 2 diabetes is restricted to a specific target organ of insulin action or represents a generalized failure to respond to insulin. It has generally been held that patients with type 2 diabetes are primarily insulin resistant in muscle and adipose tissue. However, recent studies from our laboratories have challenged the view that isolated insulin resistance in muscle and/or adipose tissue is sufficient to set in motion the complex metabolic changes that eventuate in clinical diabetes $(4,5)$. On the other hand, we have also shown that the insulin signaling pathway plays a heretofore unsuspected role in $\beta$-cell function. For example, selective ablation of insulin receptors in the $\beta$ cell results in a blunted insulin response to glucose (6), whereas ablation of irs- 2 results in impaired differentiation of $\beta$ cells and peripheral insulin resistance with consequent death from hyperosmolar nonketotic coma (7). These studies have suggested that abnormalities of insulin signaling could account for the 2 principal metabolic abnormalities found in type 2 diabetes.

The role of IRS molecules as mediators of insulin signaling through the insulin receptor is firmly established (8). It is less clear whether different IRS molecules play redundant or selective roles in insulin action in different tissues (9). Results from targeted gene ablations in mice provide interesting clues as to the interactions of insulin and IGF-1 receptors with various IRS molecules. Ablation of insulin or IGF-1 receptors results in early postnatal death caused, respectively, by diabetes or dwarfism with failure to thrive $(10,11)$. Ablation of irs-1 results in growth retardation and mild insulin resistance $(12,13)$, whereas ablation of irs-2 causes death due to a combination of insulin resistance and failure to develop compensatory response of $\beta$ cells (7). Ablation of irs-3 and irs-4 yields no apparent phenotype, raising the question of whether these 2 molecules play any role in insulin and IGF signaling $(14,15)$. The different phenotypes caused by ablation of the 2 receptors or ablation of their substrates suggest that multiple substrates are required to mediate the actions of each receptor. One possible scenario based on these 
findings is that IGF-1 receptors, perhaps acting more through irs-1, are important for growth, whereas insulin receptors, perhaps acting more through irs-2, are important for metabolic control. Nevertheless, there are significant overlaps between the 2 signaling pathways. Insulin receptors are indeed important for embryonic growth in late gestation (16), and IGF-1 receptors can mediate metabolic responses in $i r$-deficient mice (17). Likewise, it is striking that mice lacking insulin receptors, either as a result of total ablation or as a result of $\beta$ cell-selective ablation, develop normal numbers of $\beta$ cells (ref. 6 and D. Accili, unpublished observation), whereas mice without irs-2 fail to develop a sufficient number of $\beta$ cells, and mice without irs-1 show impaired insulin secretion (18). Recent studies of a common amino acid variant of IRS-1 also suggest that irs-1 may be implicated in insulin secretion (19). Based on recent evidence, it appears that igf- $1 r$ is required for $\beta$-cell growth (20). Thus, the emerging paradigm is $\beta$-cell signaling is that $i r$, acting through irs- 1 , is important for secretion, whereas igf- $1 r$, acting through irs-2, is important for growth.

We have previously shown that combined heterozygosity for null alleles of $i r$ and irs-1 results in a synergistic impairment of insulin action in multiple tissues, leading to $\beta$-cell hyperplasia and an increased incidence of diabetes (21). In these experiments, double heterozygosity for ir and irs-1 resulted in an approximately 4-fold increase in the prevalence rate of diabetes, which is similar to the increased recurrence risk of type 2 diabetes in first degree relatives of diabetic patients (22), suggesting that an oligogenic model with 2 predisposing alleles can indeed account for the entire genetic susceptibility to type 2 diabetes $(23,24)$. Moreover, several sequence variants have been identified in the human irs1 gene, which may impair irs-1 signaling and predispose to diabetes $(19,25-28)$. These data indicate that irs-1 plays an important role in metabolic regulation.

To continue to analyze the complex interactions between insulin receptors and their substrates in multiple tissues, we have generated mice with combined mutations in ir, irs-1, and irs- 2 and characterized their phenotypes.

\section{Methods}

Animal production and genotyping. Generation of mice with null alleles of ir (10), irs-1 (13), and irs-2 (7) has been described in previous publications. To obtain triple heterozygous knockouts, ir/irs- $2^{+/-}$mice were crossed with $\mathrm{irs}-1^{+/-}$mice. Genotyping was performed as described (21). The wild-type irs-2 allele was detected using primers $5^{\prime}$-GGCCTCTGTGGAAAATGTCTC- $3^{\prime}$ (sense) and 5'-CTGTGGCTTCCTTCAAGTGATG-3' (antisense). The null irs-2 allele was detected using primers 5'-ATATTGCTGAAGAGCTTGGCG-3' (sense) and 5'TGTATGCGGTGCTCCGGGAAG-3' (antisense). The reaction cycles are: 1 cycle at $94^{\circ} \mathrm{C}$ for 4 minutes; 30 cycles at $94^{\circ} \mathrm{C}$ for 1 minute, at $60^{\circ} \mathrm{C}$ for 1 minute, and at $72^{\circ} \mathrm{C}$ for 1 minute; and 1 cycle at $72^{\circ} \mathrm{C}$ for 7 minutes.
The product of wild-type allele is approximately 500 $\mathrm{bp}$, and that of null allele is approximately $1,000 \mathrm{bp}$.

Phenotypic analysis. Blood was drawn from the retroorbital sinus of anesthetized animals between 0900 and 1100 hours. Glucose levels were measured using a glucometer (Accucheck; Boehringer Mannheim, Indianapolis, Indiana, USA). Diabetes was defined as random plasma glucose greater than mean $+2 \mathrm{SD}$ of wild-type mice on at least 2 separate occasions. Insulin was measured in plasma samples by a RIA using a rat insulin standard (Linco, St. Charles, Missouri, USA). All assays were carried out in duplicate. Each value is the mean of 2 independent determinations. FFAs were measured in overnight fasted mice using the NEFA kit from Wako Diagnostics (Richmond, Virginia, USA). All procedures were approved by the Institutional Animal Care and Utilization Committee (NICHD Protocol \# 96-010).

Immunoprecipitation, immunoblotting, and PI3-kinase assay. Experiments were carried out in overnight-fasted, 8- to 12 -week-old mice. Animals were anesthetized by the intraperitoneal administration of sodium pentobarbital $(65 \mathrm{mg} / \mathrm{kg})$, and human insulin $(5 \mathrm{U})$ was injected through the inferior vena cava. Liver, hindlimb muscles (gluteus and soleus), and epididymal fat were removed 1 , 3 , and 4 minutes after insulin injection, respectively, and liver and muscle were homogenized in homogenization buffer-A (20 mM Tris [pH 7.6], 10\% glycerol, 1\% NP-40, $140 \mathrm{mM}$ sodium chloride, $2.5 \mathrm{mM}$ calcium chloride, 1 $\mathrm{mM}$ magnesium chloride, $1 \mathrm{mM}$ sodium orthovanadate, $1 \mathrm{mM}$ dithiothreitol, and $1 \mathrm{mM}$ phenylmethylsulfonyl fluoride). For PI 3-kinase assay, $7.5 \mathrm{mg}$ of liver extracts and $5 \mathrm{mg}$ of muscle extracts were immunoprecipitated with antiphosphotyrosine antibodies (Transduction Laboratories, Lexington, Kentucky, USA). The immunocomplexes were washed and resuspended in $20 \mu \mathrm{L}$ of phosphatidylinositol $(0.5 \mathrm{mg} / \mathrm{mL})$ sonicated with $25 \mathrm{mM}$ HEPES (pH 7.1), $0.5 \mathrm{mM}$ EGTA, and $0.5 \mathrm{mM}$ sodium phosphate. The phosphorylation reaction was started by the addition of $10 \mu \mathrm{L}$ of $250 \mu \mathrm{M}$ ATP containing $5 \mu \mathrm{Ci}$ of $\left[\gamma^{32} \mathrm{P}\right] A T P$ and incubated for 6 minutes at room temperature. The reaction was stopped by adding $15 \mu \mathrm{L}$ of $4 \mathrm{~N}$ $\mathrm{HCl}$. Phospholipids were extracted with $130 \mu \mathrm{L}$ of $\mathrm{CHCl}_{3} /$ methanol (1:1), and $30 \mu \mathrm{L}$ of the $\mathrm{CHCl}_{3}$ layer was resolved on thin layer chromatography plates. Radiolabeled spots corresponding to PI3-monophosphate were quantitated with NIH Image software (version 1.6; National Institutes of Health, Bethesda, Maryland, USA). Epididymal fat pads were homogenized in buffer-B (20 mM Tris [pH 7.6], $10 \%$ glycerol, $1 \% \mathrm{NP}-40,137 \mathrm{mM} \mathrm{NaCl}$, $2 \mathrm{mM}$ EDTA, $1 \mathrm{mM}$ sodium orthovanadate, and $1 \mathrm{mM}$ phenylmethylsulfonyl fluoride). The lysates were immunoprecipitated with antiphosphotyrosine antibodies coupled to protein G-agarose beads. For immunoblotting, the beads were boiled in SDS sample buffer, separated on $8 \%$ SDS-polyacrylamide gel, and transferred to nitrocellulose membranes. The filter was immunoblotted with anti-p85 antibodies (Upstate Biotechnology, Lake Placid, New York, USA). Bound anti- 
bodies were detected with horseradish peroxidase-coupled antibodies to rabbit immunoglobulin $\mathrm{G}$ using the ECL detection system (Amersham Pharmacia Biotech, Buckinghamshire, United Kingdom).

Immunohistochemistry of the pancreas and quantitation of $\beta$ cells. For analysis of adult pancreases, animals were killed by overdose of sodium amytal. Pancreata were removed, cleared of fat and spleen, weighed, and fixed overnight in Bouin's solution. Tissues were embedded in paraffin, and consecutive $5-\mu \mathrm{m}$ sections were mounted on slides. After rehydration and permeabilization in $0.1 \%$ Triton $\mathrm{X}-100$, sections were immunostained for $\alpha$ cells using mouse monoclonal antiglucagon antibodies (Sigma Chemical Co., St. Louis, Missouri, USA). $\beta$ cells were immunostained using either guinea pig anti-insulin (Linco) or mouse anti-insulin antibodies (Sigma Chemical Co.). Detection was performed using rhodamine and fluorescein antibodies (Jackson ImmunoResearch Laboratories Inc., West Grove, Pennsylvania, USA). Sections were also incubated briefly in DAPI $(0.01 \%)$ to reveal total cell nuclei. Paraffin-embedded sections were immunostained as already described here.

For quantitation of $\beta$-cell area, sections were viewed using a Zeiss Axiovert S100 TV (Zeiss Inc. Thornwood, New York, USA) microscope and video camera at $\times 200$. Two sections of each pancreas were covered systematically by accumulating images from 8 nonoverlapping fields of $1.5 \times 10^{6} \mathrm{~mm}^{2}$. Analyses of $\beta$-cell area and size were performed using Openlab image analysis software (Improvision Imaging, Coventry, United Kingdom). The magnification of each micrograph was calibrated by this software. Results are expressed as the percentage of the total surveyed area containing cells positive for insulin.

Statistical analyses. Descriptive statistics, ANOVA followed by Fisher's test and regression analysis, were performed using the Statsview software (Abacus Concepts, Inc., Berkley, California, USA).

\section{Results}

Generation of mice with combined mutations of ir, irs-1, and irs-2. ir $/$ irs-1 $1^{+/}$, ir/irs-2+/- and ir/irs- $1 /$ irs- $2^{+/-}$mice were generated by intercrossing mice heterozygous for each mutation. The 3 mutations are maintained on a mixed genetic background $(\mathrm{C} 57 \mathrm{Bl} \times 129 \mathrm{sv})$. Combinations of the 3 mutations have different effects on mouse growth (Figure 1). Although $i r^{+/-}$and $i r / i r s-2^{+/-}$mice developed normally, ir/irs-1 $1^{+/-}$and ir/irs-1/irs$2^{+/-}$mice show mild growth retardation by $17 \%$ and $22 \%$, respectively $(P<0.05)$. There is no significant difference between the growth decrease in $i r / i r s-1^{+/-}$and ir/irs-1/irs-2+/- mice.

Development of diabetes in mice with combined mutations. We first examined the development of insulin resistance and diabetes of mice with different genotypes. As

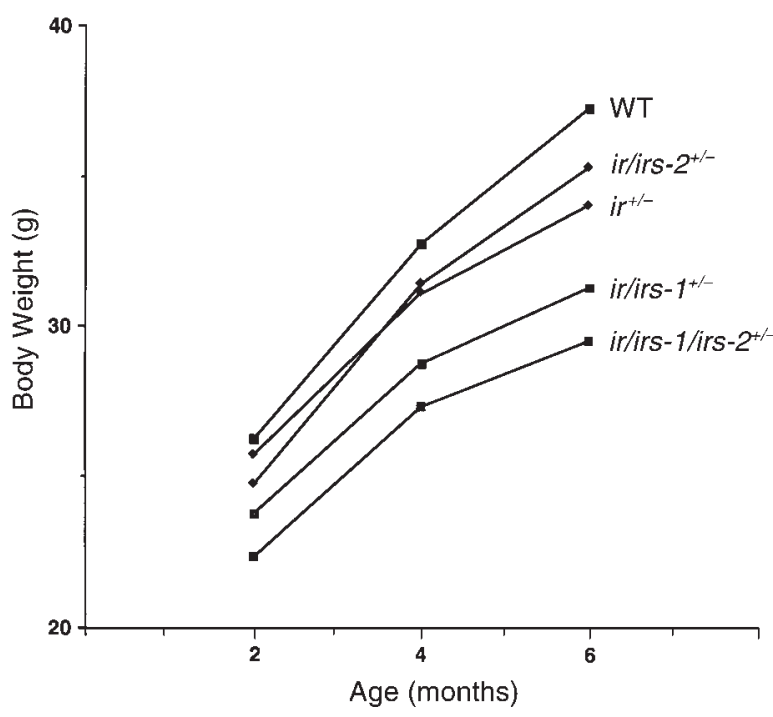

\section{Figure 1}

Growth curves of mutant mice. Mice were weighed at 2, 4, and 6 months. Each point represents the mean body weight of at least 25 mice for each genotype. The SEM is not shown and was less than $3 \%$ at each time point for each genotype. $P<0.05$ for $\mathrm{ir} / \mathrm{irs}-1^{+/-}$or $\mathrm{ir} / \mathrm{irs}-$ $1 /$ irs- $2^{+/-}$versus wild-type, ir ${ }^{+/-}$and $\mathrm{ir} / \mathrm{irs}-2^{+/-} . P=\mathrm{NS}$ for $\mathrm{ir} / \mathrm{irs}-1^{+/-}$versus $\mathrm{ir} / \mathrm{irs}-1 / \mathrm{irs}^{-2^{+/}}$.

observed in previous studies $(21,29)$, insulin resistance and diabetes developed almost exclusively in male mice. Therefore, all ensuing studies were performed in male mice. Figure 2 shows blood glucose values at different ages in mice of different genotypes. At 2 months of age, glucose values were not significantly different among mice of different genotypes. In wild-type and $\mathrm{ir}^{+/-}$mice, glucose levels decreased by approximately $10 \%$ between 2 and 6 months. In contrast, in double and triple heterozygotes, glucose levels increased at 6 months, consistent with a chronic process that results in progressive deterioration of glucose homeostasis. The data for adult animals (6 months old) are summarized in Table 1. As in previous studies, the low prevalence of diabetes in $\mathrm{ir}^{+/-}$ mice ( $5 \%$ in this cross) increased approximately 4 -fold in $\mathrm{ir} / \mathrm{irs}-\mathrm{1}^{+/-}$mice $(20 \%)$. Combined heterozygosity for $\mathrm{ir} / \mathrm{irs}-$ $2^{+/-}$yielded a slightly lower prevalence rate $(17 \%)$, whereas triple heterozygous ir/irs-1/irs-2+/- mice developed hyperglycemia at a rate of $40 \%$. The highest glucose levels were observed in triple heterozygous knockouts, with lesser increases in double heterozygotes. Plasma insulin
Table 1

Metabolic data of 6-month-old mice

\begin{tabular}{lcccccc}
\hline $\begin{array}{l}\text { Genotype } \\
(n)\end{array}$ & $\begin{array}{c}\text { Body weight } \\
(\mathrm{gm})\end{array}$ & $\begin{array}{c}\text { Glucose } \\
(\mathrm{mg} / \mathrm{dL})\end{array}$ & $\begin{array}{c}\text { Fed insulin } \\
(\mathrm{ng} / \mathrm{mL})\end{array}$ & $\begin{array}{c}\text { Fasting insulin } \\
(\mathrm{ng} / \mathrm{mL})\end{array}$ & $\begin{array}{c}\text { FFA } \\
(\mathrm{mEq} / \mathrm{L})\end{array}$ & $\begin{array}{c}\text { Diabetic } \\
(\%)\end{array}$ \\
Wild-type (42) & $37.2 \pm 1.0$ & $176 \pm 5$ & $2.9 \pm 0.7$ & $0.6 \pm 0.1$ & $0.74 \pm 0.06$ & 0 \\
ir $^{+/-}(58)$ & $34.1 \pm 0.6^{\mathrm{A}}$ & $172 \pm 6$ & $12.1 \pm 3.0$ & $1.5 \pm 0.7$ & $0.64 \pm 0.05$ & 5 \\
ir/irs-1 $^{+/-}(35)$ & $31.1 \pm 0.5^{\mathrm{A}}$ & $198 \pm 13$ & $48.2 \pm 8.6^{\mathrm{A}}$ & $3.9 \pm 2.3$ & $0.59 \pm 0.09$ & 20 \\
ir/irs-2 $2^{+/-}(35)$ & $35.2 \pm 0.8$ & $209 \pm 17^{\mathrm{A}}$ & $15.6 \pm 3.8^{\mathrm{A}}$ & $1.2 \pm 0.2$ & $0.63 \pm 0.14$ & 17 \\
ir/irs-1/irs-2 & $29.3 \pm 0.7^{\mathrm{A}}$ & $238 \pm 24^{\mathrm{A}}$ & $39.6 \pm 13.6^{\mathrm{A}}$ & $3.7 \pm 1.8$ & $0.57 \pm 0.07$ & 40
\end{tabular}

The data represent mean \pm SEM. ${ }^{A} P<0.05$ versus wild-type mice. 
a

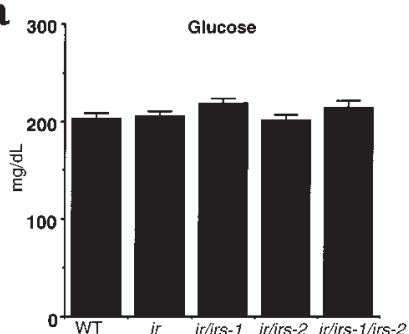

b
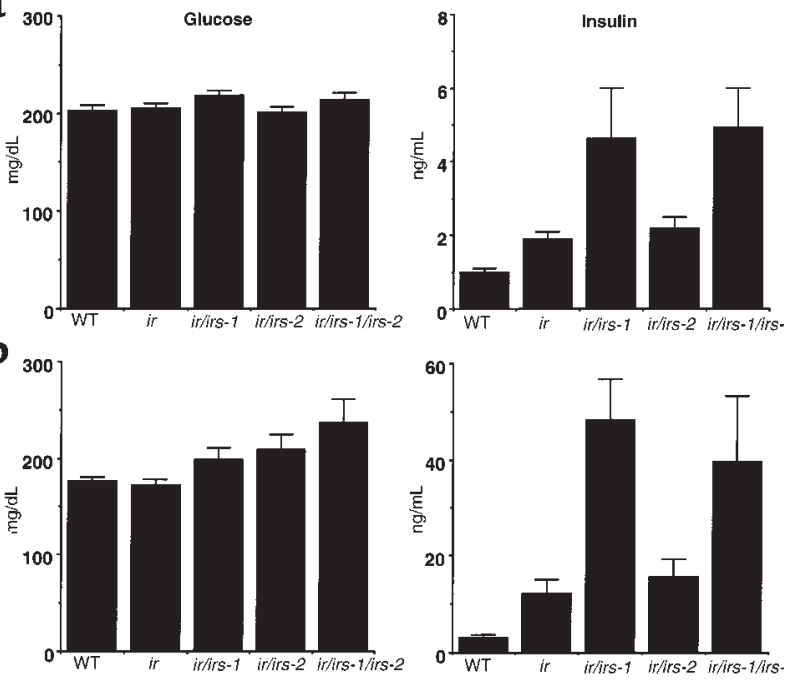

Figure 2

Effect of combined ir and irs-1 and/or irs-2 mutations on glucose and insulin levels. (a) Whole blood glucose levels in animals of the indicated genotype. (b) Plasma insulin levels as measured by RIA. Values were determined in fed mice between 0900 and 1100 hours at 2 and 6 months of age. The results represent means of at least 30 wild-type,

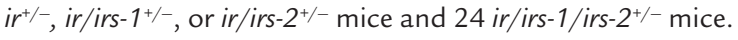

levels increased with age in all mice, regardless of the genotype. However, the increase in wild-type mice was rather modest $(3.5 \mathrm{ng} / \mathrm{mL}$ at 6 month compared with 1.0 $\mathrm{ng} / \mathrm{mL}$ at 2 months). The steepest increase was seen in $\mathrm{ir} / \mathrm{irs}^{-1^{+/-}}$and in triple heterozygotes, in which insulin levels reached levels 17- and 14-fold higher, respectively, than normal controls. The rise in $\mathrm{r}^{+/-}$and $\mathrm{ir} / \mathrm{irs}-2^{+/-}$was less marked, with levels approximately 4 - and 5 -fold higher than wild-type mice, respectively (Figure 2 and Table 1). None of the mutations was associated with significant increases in FFA concentrations (Table 1).

Correlation between insulin resistance and byperglycemia. The metabolic data are consistent with the hypothesis that both irs-1 and irs-2 contribute to the pathogenesis of diabetes in this cross. There are, however, considerable differences in insulin values in the $\mathrm{ir} / \mathrm{irs}^{-1^{+/-}}$and $\mathrm{ir} / \mathrm{irs}-2^{+/-}$ strains ( 48 vs. $15 \mathrm{ng} / \mathrm{mL}$ ). This suggests that the pathogenesis of diabetes may differ in each subgroup of mice and suggests clues as to the in vivo role of each substrate. The correlation between insulin resistance and the development of diabetes is analyzed in the data presented in Figure 3. Figure 3 a shows a scattergram correlating insulin and glucose values in each cross. The data show a bellshaped distribution, as we observed previously for $\mathrm{ir}^{+/}$ mice (29). We can distinguish 3 groups of mice: normoglycemic/mildly hyperinsulinemic (glucose $<200 \mathrm{mg} / \mathrm{dL}$; insulin $<50 \mathrm{ng} / \mathrm{mL}$ ), mildly hyperglycemic/severely hyperinsulinemic (glucose $>200<300 \mathrm{mg} / \mathrm{dL}$; insulin $>50$ $\mathrm{ng} / \mathrm{mL}$ ), and frankly hyperglycemic/mildly hyperinsulinemic (glucose $>400 \mathrm{mg} / \mathrm{dL}$; insulin $<50 \mathrm{ng} / \mathrm{mL}$ ). This horseshoe-shaped correlation between insulin and glucose is typical of type 2 diabetes and suggests that $\beta$ cell function is affected by increasing glucose levels.

In Figure 3b, we compared insulin levels in diabetic and nondiabetic mice within the same genotype. In $\mathrm{ir}^{+/-}$and $\mathrm{ir} / \mathrm{irs}^{-1^{+/-}}$or $\mathrm{ir} / \mathrm{irs}-2^{+/-}$double heterozygotes, diabetic mice show the highest insulin levels, consistent with the model that diabetes is a result of insulin resistance and that $\beta$-cell failure does not play an important role in this process. In contrast, in triple heterozygous mice, diabetic and nondiabetic mice show similar insulin levels, suggesting that hyperglycemia results from the inability of the $\beta$ cell to compensate for peripheral insulin resistance.

Impaired insulin-stimulated PI 3-kinase activity in skeletal muscle, liver, and adipose tissue. We next examined insulin action in selected target organs from diabetic and nondiabetic mice with various combinations of mutations. For these experiments, overnight-fasted animals were injected with a bolus of human insulin, and liver, skeletal muscle, and epididymal fat were collected at differ- a

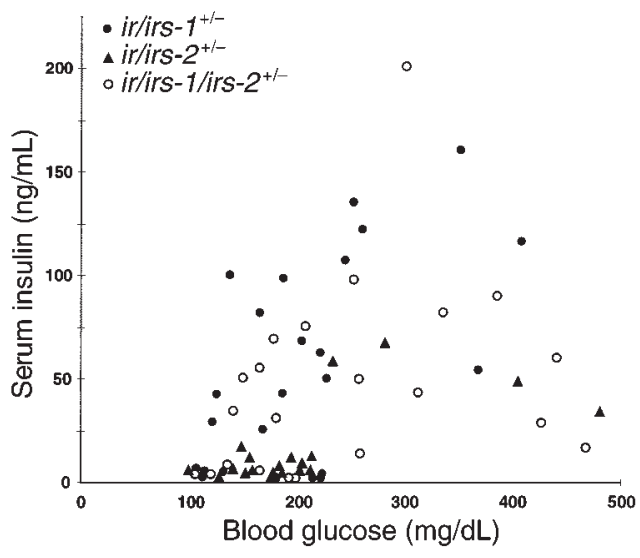

b

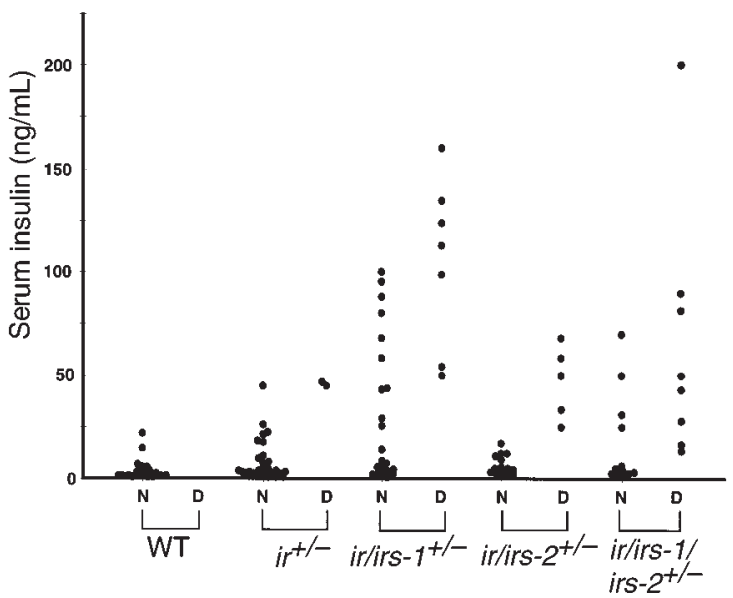

Figure 3

Correlation between insulin and glucose values. (a) Scattergram representation of plasma insulin and glucose values in ir/irs- $1^{+/-}($filled circles), $\mathrm{ir} / \mathrm{irs}-2^{+/-}$(filled triangles), and $\mathrm{ir} / \mathrm{irs}-1 / \mathrm{irs}-2^{+/-}$mice (open circles). All mice were studied at 6 months of age. (b) Serum insulin values in nondiabetic $(\mathrm{N})$ and diabetic (D) animals of the indicated genotype at 6 months of age. 
ent time points. Because of the pivotal role of PI 3kinase in mediating the biologic actions of insulin through irs-1 and-2, we measured the activation of PI 3kinase as an indicator of insulin action. Because identical results were obtained in diabetic and nondiabetic animals, only data from the diabetic group are shown. In liver extracts (Figure 4a), insulin-dependent PI 3kinase activity was reduced by $30 \%$ in $\mathrm{ir}^{+/-}$mice, $50 \%$ in $\mathrm{ir} / \mathrm{irs}-1^{+/-}, 60 \%$ in $\mathrm{ir} / \mathrm{irs}-2^{+/-}$, and $70 \%$ in triple heterozygotes. In muscle extracts (Figure 4b), insulin-dependent PI 3-kinase activity was decreased by $~ 30 \%$ in $\mathrm{ir}^{+/-}$mice, $65 \%$ in $\mathrm{ir} / \mathrm{irs}-1^{+/-}, 40 \%$ in $\mathrm{ir} / \mathrm{irs}-2^{+/-}$, and $75 \%$ in triple heterozygotes. Compared with $i^{+/-}$mice, double heterozygous $i r / i r s-1^{+/-}$showed a reduction of PI 3-kinase in both muscle and liver, whereas $\mathrm{ir} / \mathrm{irs}-2^{+/-}$displayed a profound decrease in liver, but almost no effect in skeletal muscle above that due to the $i^{+/-}$defect alone. Triple heterozygotes showed profound decreases of insulin-dependent PI 3-kinase activity in both tissues.

In epididymal fat pads, we measured coprecipitation of the regulatory p85 subunit of PI 3-kinase with antiphosphotyrosine antibodies as a surrogate measure of PI 3-kinase activation (Figure 4c). These results showed a modest $20 \%$ decrease of coprecipitable p 85 in $\mathrm{ir}^{+/-}$and $\mathrm{ir} / \mathrm{irs}-2^{+/-}$mice and a more sustained $40 \%$ decrease in $\mathrm{ir} / \mathrm{irs}-1^{+/-}$and triple heterozygotes. The conclusion of these experiments is that compared with $\mathrm{ir}^{+/-}$ mice, $i r / i r s-1^{+/-}$mice are more insulin resistant in muscle, fat, and liver, whereas $\mathrm{ir} / \mathrm{irs}-2^{+/-}$are more insulin resistant in liver, but not in muscle or fat.

Islet morphology and $\beta$-cell function. In view of the differences in circulating insulin levels between $\mathrm{ir} / \mathrm{irs}-1^{+/-}$ and $\mathrm{ir} / \mathrm{irs}-2^{+/-}$mice, we analyzed islet morphology in mice of various genotypes. As shown in Figure 5, islet size in nondiabetic mice was quite similar among the 5 different genotypes. In contrast, diabetic mice showed considerable increases in islet mass. The largest islets were observed in $\mathrm{ir} / \mathrm{irs}-1^{+/-}$and triple heterozygous mice. $\mathrm{Ir}^{+/-}$and $\mathrm{ir} / \mathrm{irs}-2^{+/-}$mice showed a less marked increase in islet size. Quantitative analysis of pancreatic sections indicated that the increase in islet size was due to increased $\beta$-cell mass (Figure $5 b$ ). Insulin levels correlated with increased $\beta$-cell mass in all groups of mice. The total pancreatic area represented by $\beta$ cells increased from $2 \%$ to $4 \%$ in $\mathrm{ir}^{+/-}$and $\mathrm{ir} / \mathrm{irs}_{-} 2^{+/-}$mice, and to $8 \%$ in $\mathrm{ir} / \mathrm{irs}-1^{+/-}$and triple heterozygous knockouts.

\section{Discussion}

Tissue-specific patterns of insulin resistance in mice with ir and irs-1 or irs- 2 mutations. In this study, we have addressed the role of irs- 1 and irs- 2 in insulin signaling in different tissues and in the pathogenesis of diabetes. Studies of mice with combined ir and irs-1 mutations have indicated that irs-1 is important to mediate insulin action in peripheral tissues. The present results provide further evidence for a tissue-specific role of irs- 1 and irs-2 in insulin signaling. Thus, $i r /$ irs $-1^{+/-}$mice are severely insulin resistant as a result of impaired insulin signaling in the 3 main sites of insulin action: skeletal mus- a

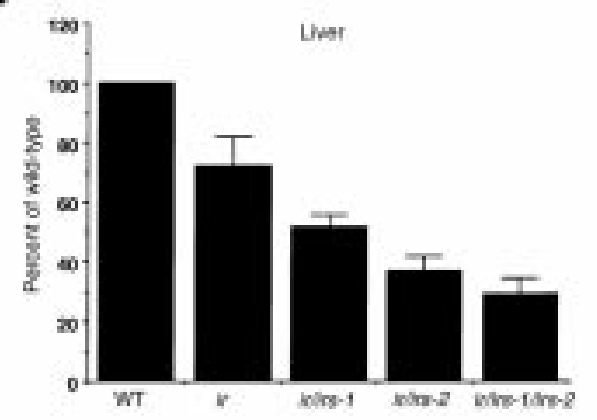

b

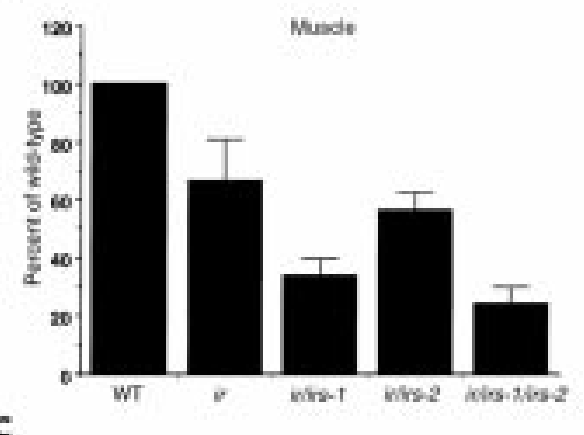

C

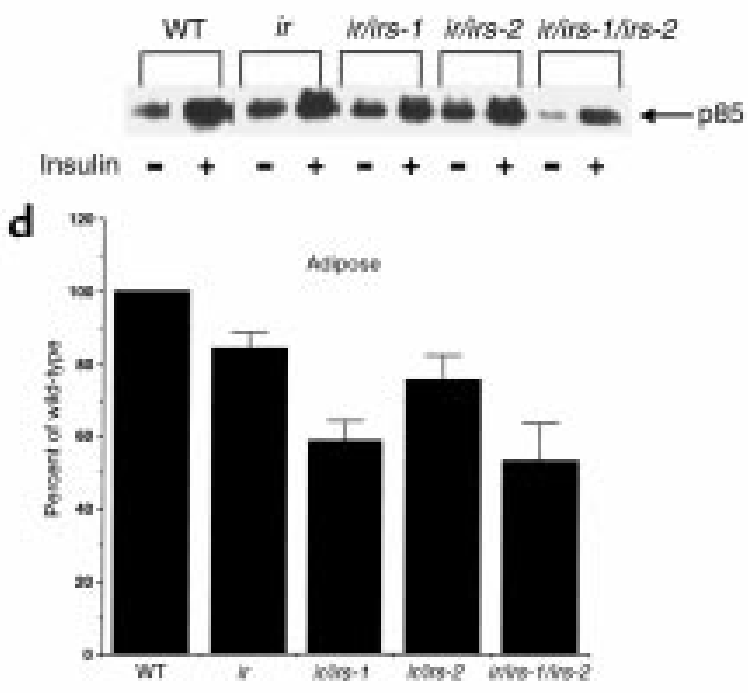

Figure 4

Insulin-stimulated PI3-kinase activity in liver and muscle. Liver (a) and hindlimb muscle (b) extracts from 8- to 12-week-old animals were immunoprecipitated with antiphosphotyrosine and subjected to PI3-kinase assay as described in Methods. The results are expressed as percentage of $\mathrm{PI} 3$-kinase activity in insulin-treated wild-type mice. The data represent mean \pm SEM from five independent experiments. ( $\boldsymbol{c}$ and $\mathbf{d}$ ) Association between p85 and phosphotyrosine-containing proteins in epididymal fat tissues. Epididymal fat pads were isolated from 8- to 12-week-old mice after insulin stimulation and solubilized as indicated. Triton-soluble proteins were immunoprecipitated with antiphosphotyrosine antibodies followed by immunoblotting with anti-p 85 antibody. A representative blot is shown (c). and quantitation of the results from 3 independent experiments is shown in the bar graphs (d). The intensity of the autoradiographic bands was quantitated using the NIH image software. The results are expressed as percentage of p85 associated with phosphotyrosine-containing proteins in insulin-stimulated wild-type mice. The data represent mean \pm SEM. 


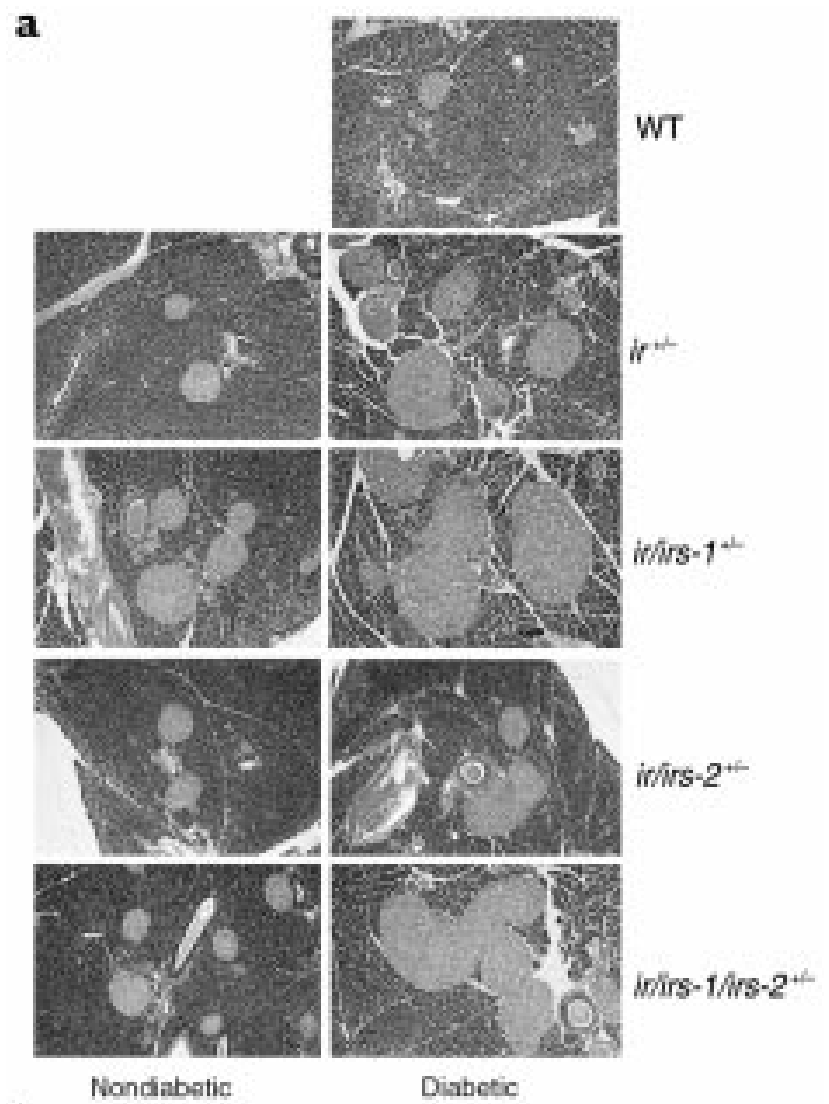

b

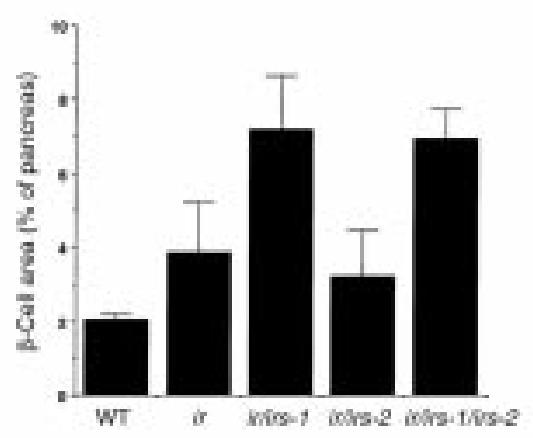

Figure 5

Islet morphology and analysis of $\beta$-cell mass in mutant mice. (a) Hematoxylin and eosin staining. Representative $\beta$-cells from diabetic and nondiabetic animals of each genotype were shown. (b) Quantitation of $\beta$-cell area in animals of the indicated genotype was performed using the Openlab image analysis software. Results are expressed as the percentage of the total surveyed area containing cells positive for insulin. Both diabetic and nondiabetic animals were studied.

cle, liver, and adipose tissue. The insulin resistance in these mice is associated with a compensatory increase of $\beta$-cell mass without alterations of insulin secretion. In contrast, $i r / i r s-2^{+/-}$mice develop relatively mild insulin resistance, but the prevalence of diabetes is comparable to $\mathrm{ir} / \mathrm{irs}-1^{+/-}$mice. This could be due to the fact that the primary site of insulin resistance in ir/irs$2^{+/-}$mice is the liver. It is well established that, regardless of the degree of muscle insulin resistance, glucose levels in diabetic (and nondiabetic) individuals are determined by the rate of hepatic glucose production, which in turn is regulated by insulin (30). These data confirm the paramount role of the liver in insulin resistance and diabetes and are consistent with the predictions of tissue-specific models of insulin resistance $(4,5,31)$. These data, however, should be extrapolated to humans with some caution, as the relative role of the liver in fuel homeostasis in humans and rodents may be quite different. For example, in rodents hepatic glycogen is about 15 -fold more abundant than muscle glycogen (D. Accili, unpublished data). Therefore, even a small variation in hepatic glucose handling has the potential of affecting whole body glucose homeostasis in a profound manner in mice.

$B$-cell growth and function in double and triple heterozygous mice. The degree of $\beta$-cell compensation to insulin resistance is different in the 3 sets of mice with $i r$ and irs-1 and/or irs- 2 mutations. In ir/irs- $1^{+/-}$mice, there is a robust compensatory $\beta$-cell growth, whereas in ir/irs$2^{+/-}$mice the degree of compensation is relatively modest, probably because insulin resistance is not as profound as in $\mathrm{ir} / \mathrm{irs}-1^{+/-}$mice or because heterozygosity for irs- 2 limits $\beta$-cell growth. In triple heterozygous knockouts, $\beta$-cell compensation, although robust, appears to be insufficient for the extreme degree of insulin resistance observed. In fact, comparisons of diabetic and nondiabetic mice within each genotype indicates that insulin levels in diabetic mice are consistently higher than in nondiabetic mice in all genotypes, except in triple heterozygous knockouts, in which insulin levels are similar in diabetic and nondiabetic animals. The hypothesis that $\beta$-cell mass is affected by haploinsufficiency for irs- 2 is consistent with the proposed role of irs-2 in the $\beta$ cell (20). The degree of $\beta$-cell compensation correlates with the degree of muscle/fat insulin resistance, rather than with hepatic insulin resistance. It is possible that $\beta$-cell proliferation is triggered in response to factors secreted by skeletal muscle or adipose tissue, or by "portal" factors that are not present in mice with hepatic insulin resistance.

Signaling by irs-1 and irs-2. Are different IRS molecules functionally interchangeable? There are 4 known IRS molecules and a related protein called Gab-1 (32-36). These molecules share a common structure composed of 2 molecular adhesives, the PH and PTB domains, and several Y-X-X-M motifs for binding $\mathrm{SH} 2$ domains of signaling proteins like PI 3-kinase (8). Sequence variations, in addition to variations in tissue distribution, provide a potential mechanism for signaling diversity by the various molecules through the formation of different signaling complexes. The gene ablation data are consistent with the notion that the 4 IRSs play very different roles in vivo. The molecular basis of this functional specificity is only beginning to be addressed $(37,38)$. The present data are consistent with the possibility that both irs1 and irs-2 are important for insulin action. The impairment of insulin action in different tissues of $\mathrm{ir} / \mathrm{irs}-1^{+/-}$and $\mathrm{ir} / \mathrm{irs}-2^{+/-}$mice correlates with the expression levels of the 2 proteins. Taken at face value, these 
data indicate that the 2 molecules have similar functions in vivo and that the key to their function lies in their different tissue distribution. Nonetheless, it should be pointed out that, in our in vivo experiments, animals were treated with large doses of insulin that may potentially activate IGF-1 receptors. Thus, to provide more definitive insight into the specificity of irs- 1 and irs- 2 downstream of insulin and IGF-1 receptors, it will be necessary to perform glucose clamps at submaximal insulin concentrations.

Genetic heterogeneity of type 2 diabetes. The genetic predisposition to type 2 diabetes does not follow a simple mendelian pattern (23). Among the explanations generally offered for this observation are genetic heterogeneity, polygenic inheritance, incomplete penetrance, phenocopies, and transmission through mitochondrial DNA (39). Our previous studies of the ir/irs-1 mouse have provided a model in which interactions among few (in our case, 2) predisposing alleles are sufficient to explain the entire genetic component of the susceptibility to type 2 diabetes (21). The present data confirm the oligogenic nature of the interactions required to cause diabetes, and provide a practical demonstration of genetic heterogeneity, in which mutations of different genes cause the same disease phenotype through different mechanisms. It is also important to note that none of the phenotypes described in this study are impervious to the effects of genetic background. Thus, even in the presence of a substantial impairment of insulin action, as seen in triple heterozygous knockouts, only a fraction of the mice develop diabetes. This is most probably due to the effect of genetic modifiers, which we have now begun to map using recombinant inbred strains carrying the ir mutation (29). It will be important to test the linkage of these loci to insulin resistance in the different strains described in this study. In summary, the present studies provide further insight into the interactions among different molecules in the insulin signaling pathway in vivo and suggest that signaling through irs-1 and irs-2 mediates a significant part of the biologic actions of insulin in different target tissues.

\section{Acknowledgments}

This work was supported in part by a grant from the American Diabetes Association to D. Accili. We thank H. Kanno for help with genotyping.

1. Kahn, C.R. 1996. New concepts in the pathogenesis of diabetes mellitus. Adv. Intern. Med. 41:285-321.

2. Taylor, S.I. 1999. Deconstructing type 2 diabetes. Cell. 97:9-12.

3. Polonsky, K.S., Sturis, J., and Bell, G.I. 1996. Non-insulin-dependent diabetes mellitus: a genetically programmed failure of the beta cell to compensate for insulin resistance. N. Engl. J. Med. 334:777-783.

4. Lauro, D., et al. 1998. Impaired glucose tolerance in mice with a targeted impairment of insulin action in muscle and adipose tissue. Nat. Genet. 20:294-298.

5. Bruning, J.C., et al. 1998. A muscle-specific insulin receptor knockout exhibits features of the metabolic syndrome of NIDDM without altering glucose tolerance. Mol. Cell. 2:559-569.

6. Kulkarni, R.N., et al. 1999. Tissue-specific knockout of the insulin receptor in pancreatic beta cells creates an insulin secretory defect similar to that in type 2 diabetes. Cell. 96:329-339.

7. Withers, D.J., et al. 1998. Disruption of IRS-2 causes type 2 diabetes in mice. Nature. 391:900-904.

8. White, M.F. 1998. The IRS-signalling system: a network of docking proteins that mediate insulin and interleukin signalling. Mol. Cell. Biochem. 182:3-11.

9. Yamauchi, Y., et al. 1996. Insulin signaling and insulin actions in the muscles and livers of insulin-resistant, insulin receptor substrate 1-deficient mice. Mol. Cell. Biol. 16:3074-3084.

10. Accili, D., et al. 1996. Early neonatal death in mice homozygous for a null allele of the insulin receptor gene. Nat. Genet. 12:106-109.

11. Liu, J.P., Baker, J., Perkins, A.S., Robertson, E.J., and Efstratiadis, A. 1993. Mice carrying null mutations of the genes encoding insulin-like growth factor I (Igf-1) and type 1 IGF receptor (Igf1r). Cell. 75:59-72.

12. Tamemoto, H., et al. 1994. Insulin resistance and growth retardation in mice lacking insulin receptor substrate-1. Nature. 372:182-186.

13. Araki, E., et al. 1994. Alternative pathway of insulin signalling in mice with targeted disruption of the IRS-1 gene. Nature. 372:186-190.

14. Lavan, B., et al. 1998. Tyrosine phosphorylation in insulin action. Proceedings of the 80th Annual Meeting of the Endocrine Society, New Orleans, LA. 36.

15. Liu, S.C.H., Wang, Q., Lienhard, G.E., and Keller, S.R. 1999. Insulin receptor substrate 3 is not essential for growth or glucose homeostasis. J. Biol. Chem. 274:18093-18099.

16. Louvi, A., Accili, D., and Efstratiadis, A. 1997. Growth-promoting interaction of IGF-II with the insulin receptor during mouse embryonic development. Dev. Biol. 189:33-48.

17. Di Cola, G., Cool, M.H., and Accili, D. 1997. Hypoglycemic effect of insulinlike growth factor-1 in mice lacking insulin receptors. J. Clin. Invest. 99:2538-2544.

18. Kulkarni, R., Winnay, J., Bruning, J., and Hanahan, D. 1998. Altered insulin secretion patterns in IRS-1 deficient pancreatic beta-cells. Diabetes. 47(Suppl. 1):A57 (Abstr.).

19. Porzio, O., et al. 1999. The Gly972 $\rightarrow$ Arg amino acid polymorphism in IRS1 impairs insulin secretion in pancreatic beta cells. J. Clin. Invest. 104:357-364.

20. Withers, D.J., et al. 1999. Irs-2 coordinates Igf-1 receptor-mediated beta-cell development and peripheral insulin signalling. Nat. Genet. 23:32-40.

21. Bruning, J.C., et al. 1997. Development of a novel polygenic model of NIDDM in mice heterozygous for IR and IRS-1 null alleles. Cell. 88:561-572.

22. Ghosh, S., and Schork, N.J. 1996. Genetic analysis of NIDDM. The study of quantitative traits. Diabetes. 45:1-14.

23. Kahn, C.R., Vicent, D., and Doria, A. 1996. Genetics of non-insulin-dependent (type-II) diabetes mellitus. Annu. Rev. Med. 47:509-531.

24. Ghosh, S., and Collins, F.S. 1996. The geneticist's approach to complex disease. Annu. Rev. Med. 47:333-353.

25. Almind, K., et al. 1993. Amino acid polymorphisms of insulin receptor substrate-1 in non-insulin-dependent diabetes mellitus. Lancet. 342:828-832.

26. Imai, Y., et al. 1994. Variant sequences of insulin receptor substrate-1 in patients with noninsulin-dependent diabetes mellitus. J. Clin. Endocrinol. Metab. 79:1655-1658.

27. Almind, K., Inoue, G., Pedersen, O., and Kahn, C.R. 1996. A common amino acid polymorphism in insulin receptor substrates-1 causes impaired insulin signaling. J. Clin. Invest. 97:2569-2575.

28. Imai, Y., Philippe, N., Sesti, G., Accili, D., and Taylor, S.I. 1997. Expression of variant forms of insulin receptor substrate-1 identified in patients with noninsulin-dependent diabetes mellitus. J. Clin. Endocrinol. Metab. 82:4201-4207.

29. Kido, Y., and Accili, D. 1998. The susceptibility to diabetes in mice carrying a null allele of the insulin receptor gene is genetically determined. Diabetes. 47(Suppl. 1):A178.

30. Cherrington, A.D. 1999. Banting Lecture 1997. Control of glucose uptake and release by the liver in vivo. Diabetes. 48:1198-1214.

31. Michael, M., et al. 1999. Liver-specific insulin receptor knockout mice are severely insulin resistant. Diabetes. 48(Suppl. 1):A10. (Abstr.)

32. Sun, X.J., et al. 1991. Structure of the insulin receptor substrate IRS-1 defines a unique signal transduction protein. Nature. 352:73-77.

33. Sun, X.J., et al. 1995. Role of IRS-2 in insulin and cytokine signalling. Nature. 377:173-177.

34. Lavan, B.E., Lane, W.S., and Lienhard, G.E. 1997. The 60-kDa phosphotyrosine protein in insulin-treated adipocytes is a new member of the insulin receptor substrate family. J. Biol. Chem. 272:11439-11443.

35. Lavan, B.E., et al. 1997. A novel 160-kDa phosphotyrosine protein in insulintreated embryonic kidney cells is a new member of the insulin receptor substrate family. J. Biol. Chem. 272:21403-21407.

36. Holgado-Madruga, M., Emlet, D.R., Moscatello, D.K., Godwin, A.K., and Wong, A.J. 1996. A Grb2-associated docking protein in EGF- and insulinreceptor signalling. Nature. 379:560-564.

37. Rother, K.I., et al. 1998. Evidence that IRS-2 phosphorylation is required for insulin action in hepatocytes. J. Biol. Chem. 273:17491-17497.

38. Bruning, J.C., Winnay, J., Cheatham, B., and Kahn, C.R. 1997. Differential signaling by insulin receptor substrate 1 (IRS-1) and IRS-2 in IRS-1-deficient cells. Mol. Cell. Biol. 17:1513-1521.

39. Lander, E.S., and Schork, N.J. 1994. Genetic dissection of complex traits. Science. 265:2037-2048. 